\title{
Nasal Septal Carcinoma
}

\author{
Taleuan A*, Benmansour N, Affelah M, Chekhhammoud Z, Elalami MN
}

Department of Otorhinolaryngology, uhc hassan ii, fes, Faculty of Medicine and Pharmacy, Sidi Mohamed Ben Abdellah University, FES, Morocco

DOI: $10.36347 /$ sjmcr.2020.v08i03.020

| Received: 27.02.2020 | Accepted: 05.03.2020 | Published: 16.03.2020

*Corresponding author: Taleuan Abdelouahid

\section{Abstract}

Introduction: Squamous cell carcinoma of the nasal septum is an uncommon entity and there are a few cases reported in the literature. It is often misdiagnosed because its symptoms are similar to everyday rhinologic complaints. The functional impact of their treatment and the high mortality makes it important to diagnose it at early stage. We report a rare case of squamous cell carcinoma of the nasal septum. Our objective is to determine the clinical and therapeutic aspects of this rare entity. Case report: A 37 years old patient with a previous pathological history: Tobacco Sniffing, has presented, bilateral nasal obstruction and recurrent epistaxis, evolving since 8 monthes. In the examination,there was seen to be a bleeding lesion of approximately $15 \times 10 \mathrm{~mm}$ that originated from the caudal end of the septum and was showing protrusion towards the right nasal cavity. Squamous cell carcinoma was reported as a result of the biopsy. The patient was treated with surgical resection and radiotherapy. No recurrence and complications were noticed after 6 months of follow-up. The patient will be programmed to reconstruct his nasal defect. Conclusion: Nasal septal carcinoma represented highly aggressive malignancies with higher rates of nodal involvement and subsequently worse outcome. Consequently, squamous cell carcinoma of the septum should be included in the differential diagnosis of any nasal obstruction that does not respond to decongestants.

Keywords: Squamous cell carcinoma, Nasal septum, hisopathology.

Copyright @ 2020: This is an open-access article distributed under the terms of the Creative Commons Attribution license which permits unrestricted use, distribution, and reproduction in any medium for non-commercial use (NonCommercial, or CC-BY-NC) provided the original author and source are credited.

\section{INTRODUCTION}

Primary squamous cell carcinoma (SCC) of the nasal septum, first reported more than a century ago, is a rare malignancy that accounts for only $9 \%$ of all malignant nasal cavity tumors [1]. SCCs of the nasal septum were already described as aggressive and often undertreated tumors with high initial nodal involvement rates (6-24\%) and early regional neck recurrences in up to $44 \%$ of cases, within the first 2 years after initial therapy [2].

The functional impact of their treatment and their high morbidity and mortality make them of paramount importance to their victims and the physicians who treat them [3]. Because of their relative infrequency, we report a rare case of SCC of the nasal septum. Our objective is to determine the clinical and therapeutic aspects of this rare entity.

\section{Case Report}

A 37 years old young man with a previous pathological history: Tobacco Sniffing. There was no history of seasonal variation and no history of allergy in the family. He has presented a bilateral nasal obstruction and recurrent epistaxis, evolving since 8 monthes. Nasal endoscopy showed a polypoid, hyperemic mass of approximately $15 \times 10 \mathrm{~mm}$ that originated from the caudal end of the septum and and was showing protrusion towards the right nasal cavity. The tumour bled easily (Fig. 1). On general examination no anaemia or enlargement of cervical lymph nodes was found. Squamous cell carcinoma was reported as a result of the biopsy. Panendoscopic examination was normal except for the septal hemorrhagic crusting mass.

Ultrasonography of the neck showed no lymphadenopathy. A computerized tomography scan was done and demonstrated a soft tissue mass of approximately $16 \times 12 \mathrm{~mm}$ limited to the end of the nasa septum with no erosion of the bone (Fig. 2). For local and distant metastases, neck, thyroid, and abdominal ultrasonography (USG), neck and thorax computed tomographies (CT) were done. No pathology was detected. Biochemical and haematological profiles were normal.

Leaving an intact surgical border of $1 \mathrm{~cm}$, the lesion was excised en bloc, including the caudal septal 
cartilage and the columella under a lateral rhinotomy. As there was no lymphadenopathy, neck dissection was not applied. The final anatomico-pathological study confirms intraepithelial cell carcinoma with free surgical borders. After multidisciplinary team meeting, postoperative radiotherapy was planned. The total dose (46 Gy) of radiation therapy was administered. No recurrence and complications were noticed after 6 months of follow-up (Fig.3). The patient will be programmed to reconstruct his nasal defect.

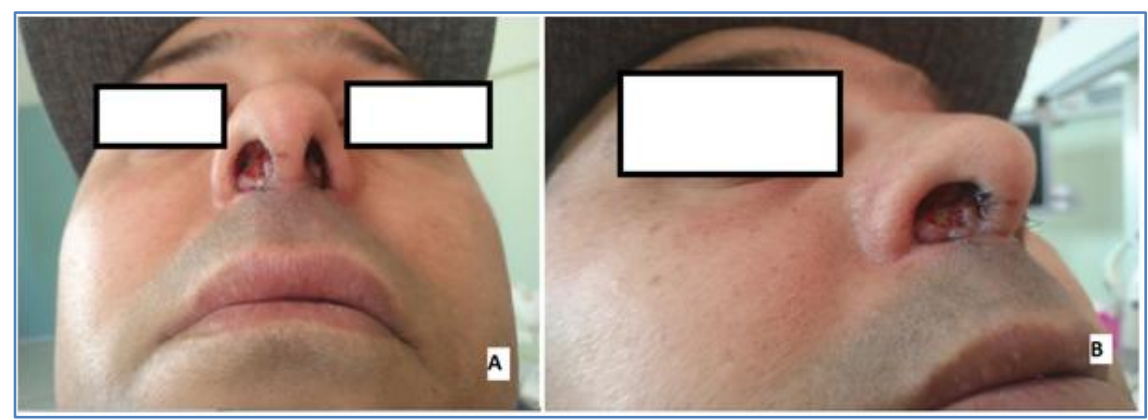

Fig-1: Photos of the patient (A and B): mass originated from the caudal end of the nasal septum with protrusion predominant tow ards the right nasal cavity

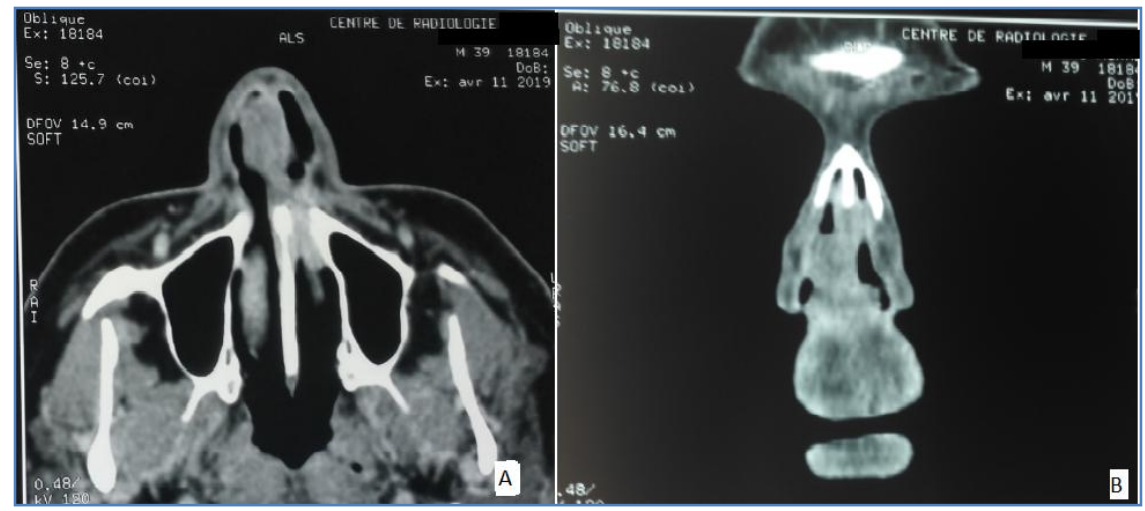

Fig-2: CT scan: axial (A) and coronal (B) plane showing soft tissue mass of the caudal end of the nasal septum measuring $16 x 12$ mm

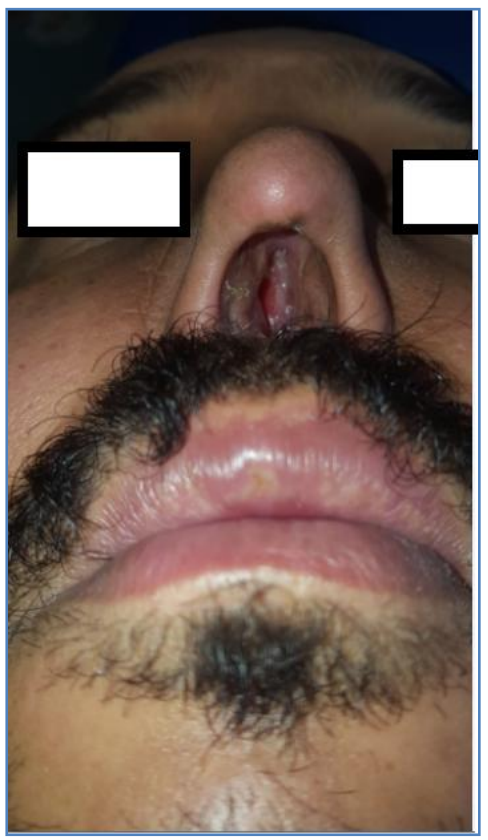

Fig-3: Appearance of the patient after resection of the primary septal carcinoma and postoperative radiotherapy

\section{DISCUSSION}

Malignancies of nasal septum are very rare malignant tumours of nose and sinuses form less than
$1 \%$ of all cancer and approximately $3 \%$ of upper respiratory and digestive tract tumours [4]. Primary nasal septum malignancies constitute $9 \%$ of sinonasal malignancies. More than two-thirds of septum cancers originate from the anterior septum and mucocutaneous junction $[5,6]$. Squamous cell carcinoma (SCC) is the most frequent histological type of nasal septal malignant tumour; the cause remains unknown. There is an increased risk of nasal carcinoma in nickel refinery workers, woodworkers, smokers and through exposure to petroleum products and solvents [7]. Nasal septum tumours are generally seen in males and in the 4th and 5 th decades of life [6]. The patient presented in this case report was a 37-year old mal, and he had history of tobacco sniffing. This demonstrates that septal squamous cell carcinoma may emerge at an earlier age with tobacco sniffing as a probable risk factor.

The symptoms are generally non-specific with nasal obstruction and recurrent epistaxis reported. Most common symptoms of septal carcinomas are nasal obstruction, recurrent epistaxis, nasal discharge, facial pain, nasal mass, and orbital complaints such as epiphora, diplopia, proptosis [8]. In our case the main symptoms were nasal obstruction and recurrent epistaxis. As the complaints are non-specific, diagnosis may be delayed. The most common examination 
findings are mucosal ulceration, mass lesion, polyp, nasal deformity and perforations. The incidence of palpable cervical lymphadenopathy ranges from $10 \%$ to $44 \%$, with most series reporting greater than $20 \%$. In addition, carcinoma of the nasal septum has been associated with other malignant tumors in $20 \%$ to $30 \%$ of reported cases [1]. The biopsy of the lesion for histopathological examination is the only method to confirm the diagnosis. To determine local spread of the disease, MR imaging is necessary and for lymph node spread and distant metastasis, ultrasonography and computed tomography imaging [5]. There is no standardised classification system because of the limited numbers of this rarely seen disease [6]. All sinonasal malignancies are staged according to the American Joint Committee on Cancer classification [6, 9].

From the literature, it is difficult to establish any meaningful cure rates and optimal treatment for nasal septal carcinoma because of the infrequent occurrence of the tumor, the variable treatments given, and the many years required to collect the data. Various treatment modalities have been advocated, including surgery alone radiotherapy alone, or combined therapy advocated by Lyons and Schaefer and Hill [10].

Because of the high recurrence rate and low cure rate with local surgical resection or local irradiation alone, many authors believe that wide-field resection with post-operative irradiation is the treatment of choice if survival in patients with this disease is to be improved [3]. The surgical approach is modified for the individual tumor [3]. It is important to obtain at least 1 $\mathrm{cm}$. tumour-clear margins to be sure of effective control. An external rhinoplasty approach (lateral rhinotomy incision) is effective in providing sufficient access for lesions confined to the septum [4]. With developments in endoscopic applications, excellent results have been obtained cosmetically and in terms of tumour control in the early stage of the disease. In patients with lymphadenopathy, a neck dissection should be added [8]. Postoperative radiotherapy is applied to reduce the recurrence rate in large lesions. After ensuring that the tumour has been completely cleared, nose reconstruction with surgery or prosthesis should be applied [5, 11]. Nasal septal carcinomas have better prognosis when diagnosed earlier. The most important prognostic factor is tumor stage [8].

\section{CONCLUSION}

Nasal septal carcinoma represented highly aggressive malignancies with higher rates of nodal involvement and subsequently worse outcome. Consequently, squamous cell carcinoma of the septum should be included in the differential diagnosis of any nasal obstruction that does not respond to decongestants.

\section{REFERENCES}

1. Leeman DJ, Shuler KJ, Han K, Mirani N. Dedifferentiation of primary squamous cell carcinoma arising from the nasal septum. Otolaryngol--Head Neck Surg Off J Am Acad Otolaryngol-Head Neck Surg. 1996;114(1):131- 6.

2. Janik S, Gramberger M, Kadletz L, Pammer J, Grasl MC, Erovic BM. Impact of anatomic origin of primary squamous cell carcinomas of the nasal cavity and ethmoidal sinus on clinical outcome. Eur Arch Oto-Rhino-Laryngol Off J Eur Fed OtoRhino-Laryngol Soc EUFOS Affil Ger Soc OtoRhino-Laryngol - Head Neck Surg. 2018;275(9):2363- 71.

3. McGuirt WF, Thompson JN. Surgical approaches to malignant tumors of the nasal septum. The Laryngoscope. 1984;94(8):1045- 9.

4. Jan A, Department ENT. Squamous cell carcinoma of nasal septum. JPMA. 1986 ; 36: 269-2.

5. Ho YM, Coman WB. Nasal septum malignancy. ANZ J Surg. 2011;81(7-8):533- 6.

6. Fornelli RA, Fedok FG, Wilson EP, Rodman SM. Squamous cell carcinoma of the anterior nasal cavity: a dual institution review. Otolaryngol-Head Neck Surg Off J Am Acad Otolaryngol-Head Neck Surg. 2000;123(3):207- 10.

7. Echeverria-Zumarraga M, Kaiser C, Gavilan C. Nasal septal carcinoma: initial symptom of nasal septal perforation. J Laryngol Otol. 1988;102(9):834 - 5.

8. Çukurova I, Gümüşsoy M, Kaptaner S, Uğur O, Iber M, Arslan IB. Squamous cell carcinoma originating from the nasal septal perforation: a rare nasal tumor. Kulak Burun Bogaz Ihtis Derg KBB J Ear Nose Throat. 2014;24(3):177- 80.

9. Allen MW, Schwartz DL, Rana V, Adapala P, Morrison WH, Hanna EY. Long-term radiotherapy outcomes for nasal cavity and septal cancers. Int J Radiat Oncol Biol Phys. 2008;71(2):401 - 6.

10. LeLiever WC, Bailey BJ, Griffiths C. Carcinoma of the nasal septum. Arch Otolaryngol Chic Ill 1960. 1984;110(11):748- 51.

11. NaBadalung DP. Prosthetic rehabilitation of a total rhinectomy patient resulting from squamous cell carcinoma of the nasal septum: a clinical report. J Prosthet Dent. 2003;89(3):234- 8. 